\title{
Genç Yetişkin Bireylerde Edinsel Beyin Hasarı Sonrası Psikososyal Uyum
}

Psychosocial Adjustment After Acquired Brain Injury in Young Adult Individuals

\author{
Özgü INAL ${ }^{1}$, Halil İbrahim ERGEN ${ }^{2}$, Esra AKI ${ }^{3}$ \\ ${ }_{1}^{1}$ Dr. Öğr. Üyesi, Trakya Üniversitesi, Sağlık Bilimleri Fakültesi, Ergoterapi Bölümü, Edirne, Türkiye \\ ${ }^{2}$ Öğr. Gör., Sanko Üniversitesi, Sağlık Bilimleri Fakültesi, Fizyoterapi ve Rehabilitasyon Bölümü, Gaziantep, Türkiye \\ ${ }^{3}$ Prof. Dr., Hacettepe Üniversitesi, Sağlık Bilimleri Fakültesi, Ergoterapi Bölümü, Ankara, Türkiye
}

\section{ÖZ}

\begin{abstract}
Amaç: Edinsel beyin hasarı (EBH); sağ kalanlarda klinik sonucu ve yaşam kalitesini etkileyen çeşitli durumları içerir ve yeti yitiminin önemli bir nedenidir. EBH sonrası bazı bireyler daha iyi bir adaptasyon süreci izlerken, bazılarının ise günlük yaşamlarında uzun süreli adaptasyon güçlüğü yaşadıkları belirtilmiştir. Bu çalışma genç yetişkin bireylerde EBH sonrası psikososyal uyumu incelemek amacı ile planlandı. Gereç ve Yöntem: Çalışmada araştırma ekibinin hazırladığı sosyo-demografik bilgi formu ve Hastalığa Psikososyal Uyum Öz-Bildirim Ölçeği kulanıldı. Çalışmada ayrıca, genç yetişkin bireylerin hastalık sonrası etkilenme biçimlerini anlamak amacıyla, bireylerle yarı yapılandırılmış görüşme yapıldı. Sonuçlar: Sekiz erkek ve üç kadın birey ile tamamlanan çalışmada; EBH sonrası genç yetişkin bireylerde psikososyal uyumun daha çok orta ve kötü düzeyde olduğu saptandı. Ayrıca bireylerin özellikle serbest zaman ve üretkenlik aktiviteleri ile ilgili olarak zorluk yaşadıkları belirlendi. Tartışma: Çalışma EBH sonrası psikososyal uyum ile ilgili yeni bilgiler sağlamaktadır. Bununla birlikte ileride daha fazla bireyin dahil edildiği ve psikososyal uyumu etkileyen faktörlerin de incelendiği çalışmaların yapılması planlanacak müdahale programları açısından yol gösterici olacaktır.
\end{abstract}

Anahtar kelimeler: Beyin hasarı; psikososyal destek sistemleri; ergoterapi; uyum

\section{ABSTRACT}

Purpose: Acquired brain injury $(\mathrm{ABI})$ includes various conditions that affect the clinical outcome and quality of life in survivors and is an important cause of disability. It has been stated that some individuals follow a better adaptation/adjustment process after $\mathrm{ABI}$, while others experience long-term adaptation/adjustment difficulties in their daily lives. This study was planned to examine psychosocial adjustment in young adult individuals after ABI. Material and Methods: In the study, the sociodemographic data form prepared by the study team and the The Psychosocial Adjustment to Illness Scale - Self-Report were used. The study also conducted a semi-structured interview with individuals to understand how young adults are affected. Results: In this study completed with eight male and three female individuals, it was found that psychosocial adjustment in young adult individuals after $A B I$ was mostly moderate and poor. In addition, it was determined that individuals experienced difficulties especially with regard to leisure time and productivity activities. Discussion: This study provides new information on psychosocial adjustment after $A B I$. However, further studies involving more individuals and examining the factors affecting psychosocial adjustment will be guiding in terms of planned intervention programs.

Keywords: Brain injury; psychosocial support systems; occupational therapy; adjustment 

Edinsel beyin hasarı (EBH) terimi, meydana gelen hasar sonrası sağ kalanlarda klinik sonucu ve yaşam kalitesini etkileyen çeşitli koşulları içerir ve yeti yitiminin önemli bir nedenidir (Feigin, Forouzanfar, Krishnamurthi ve ark., 2014; Menon ve Bryant, 2019). En yaygın nedenler arasında travmatik beyin hasarı ( $\mathrm{TBH}$ ), inme ve kardiyak arrest sonrası hipoksik-iskemik ensefalopati bulunur. EBH tanısı olan bireyler, motor ve bilişsel bozukluklar, dil ve konuşma sorunları ve duygusal problemler gibi çok çeşitli sorunlarla karşı karşıyadır ve tüm bunlar günlük yaşam aktivitelerinde bağımsızlık kaybına ve sağlıkla ilgili yaşam kalitesinin azalmasına neden olur (Bradt, Magee, Dileo ve ark., 2010).

Literatürde "adaptasyon", "uyum", "kabul" ve "başa çıkma" terimleri genellikle eşanlamlı olarak kullanılmaktadır (Yates, 2003). Bununla birlikte aslında anlamları ve kapsamları birbirinden farklılıklar içermektedir. Uyum; etkili bir şekilde baş etme ve uzlaşma sürecini içerir. Bireyin çevreden gelen değişiklikleri kabul etmesi ve bu değişikliklere uygun tutum ve davranışları gösterebilmesidir (Beck, Rawlins ve Williams, 1984). Psikososyal uyum, devamlılık, süreç, değişim, etkileşim, etki gibi özellikleri ifade etmektedir (Londono ve Mcmillan, 2015).

Dünya Sağlık Örgütü (DSÖ), 2001 yılında oluşturduğu İşlevsellik, Yetiyitimi ve Sağlığın Uluslararası Sınıflandırılması (International Classification of Functioning, Disability and Health, ICF) ile işlevsellik, yetiyitimi ve sağlık anlayışımıza yeni bir bakış açısı oluşturmuştur. ICF sağlığı, biyolojik, kişisel ve sosyal yönleri de dâhil olmak üzere, birçok açıdan ele almaktadır (WHO, 2001; Bruyère, Van Looy ve Peterson, 2005). Bu kapsamda; hastalıkların oluşumunda biyolojik, psikolojik ve sosyal etmenlerin etkileşiminin rolünü vurgulayan biyopsikososyal model kavramı daha çok öne çıkmıştır (George ve Engel, 1980). Bu durum ise; psikososyal konulara ve süreçlere, edinilmiş yeti yitimine ve kronik hastalığa uyum veya adaptasyon konularına olan ilginin artmasına neden olmuştur (McGillion, WattWatson, Kim ve ark., 2004; McGillion, WattWatson, Stevens ve ark., 2008). Bireyin, hastalık süreci ile birlikte yaşamında oluşan değişikliklere uyum sağlaması tedavi süreci ve yaşam kalitesi açısından önemlidir (Erşan, Kelleci ve Baysal, 2013; Sullivan ve Hawthrone, 1996). Ayrıca; edinsel yeti yitimi olan bireylerdeki psikososyal uyum sorunları, uzun vadeli toplum refahı ve sağlık hizmetlerinin kullanımı açısından da büyük maliyetlerle ilişkilendirilmiştir (Browne, Arpin, Corey ve ark., 1990).

EBH sonrası bazı bireyler daha iyi bir adaptasyon süreci izlerken, bazılarının ise günlük yaşamlarında uzun süreli adaptasyon güçlüğü yaşadıkları belirtilmiştir (Antonak, Liveneh ve Antonak, 1993). Literatürde bu konuda standardize yöntemlerin kullanıldığı çalışmalar yapılmış (DeDios-Stern ve Lee, 2017; Honan, McDonald, Tate ve ark., 2019), ancak kişilerin kendi bakış açılarıyla psikososyal uyumlarını yansıttığı çalışmaların kısıtlı olduğu belirlenmiştir (Ownsworth ve Fleming, 2005; Franulic, Carbonell, Pinto ve ark., 2004). Bu konudaki eksiklikten yola çıkarak; bu çalışma genç yetişkin bireylerde $\mathrm{EBH}$ sonrası psikososyal uyumu incelemek amacı ile planlandı.

\section{GEREÇ VE YÖNTEM}

Çalışmaya 19-40 yaş arası, okur-yazar, inme ve TBH tanısı bulunan ve etiyoloji tarihi üzerinden en az 6 ay geçmiş, Mini-mental testten (Güngen, Ertan, Eker ve ark., 2002) 24 puan ve üzeri alan, Modifiye Rankin Skalasına (Rankin, 1957) göre 3 ve üzeri seviyede olan 11 birey dahil edildi. Çalışma için gerekli etik kurul izni alındı (TÜTF-BAEK 2018/318).

Çalışmada araştırma ekibinin hazırladığı sosyodemografik bilgi formu ve Hastalığa Psikososyal Uyum Öz-Bildirim Ölçeği (PAIS-SR) (Adaylar, 1995; Derogatis, 1986) kulanıldı.

Hastalığa Psikososyal Uyum Öz-Bildirim Ölçeği (PAIS-SR) (Adaylar, 1995; Derogatis, 1986); 7 psikososyal uyum alanının yer aldığı 46 sorudan oluşmaktadır. Ölçeğin alt alanları; "sağlık bakımına oryantasyon", "mesleki çevre", "aile çevresi", "cinsel ilişkiler", "geniş aile ilişkileri”, "sosyal çevre" ve "psikolojik baskı" dır. Her bir soru için uyum seviyesini 0 ile 3 arasında belirleyen 4 ifade yer almaktadır. Soruya verilen olumlu ifade '0' puan, olumsuz ifade ise ' 3 ' puan ile puanlandırılmaktadır. PAIS-SR ile yapılan çalışmalarda 35 puanın altı, psikososyal uyumun "iyi", 35-51 arası puan, psikososyal uyumun "orta" ve 51 puanın üzeri ise psikososyal uyumun "kötü" olduğunu göstermektedir.

Araştırmada ayrıca, genç yetişkin bireylerin hastalık sonrası etkilenme biçimlerini anlamak amacıyla, bireylerle yarı yapılandırılmış görüşme yapıldı. Görüşme kapsamında bireylere; "Kendini hastalık öncesi bir kelime ile tanımlarsan ne söylersin?, "Kendini hastalık sonrası bir kelime ile tanımlarsan ne söylersin?", "Hastalık hayatını nasıl etkiledi?", "Hastalık sonrası kaygıların var mı?", "Hastalık sonrası beklentilerin var mı?", "Hastalık sonrası sosyal çevrende bir değişiklik oldu mu?" ve "Elinde olsa neyi değiştirirdin?" soruları yöneltildi. Görüşmeler sırasında 
bireylerin ifadeleri kalemle not tutmak şeklinde kaydedildi.

Istatistiksel Analiz

Sosyo-demografik veriler frekans ve ortalama standart sapma olarak verildi. Nitel veriler betimsel ve içerik analizi yöntemleri ile analiz edildi.

\section{SONUÇLAR}

Çalışma 8 erkek ve 3 kadın birey ile tamamlandı. Bireylerin tanımlayıcı özelikleri Tablo 1'de verilmiştir. Çalışmaya katılan bireylerin PAIS-SR sonuçları Tablo 2'de verilmiştir.

Tablo 1. Bireylerin Tanımlayıcı Özellikleri

\begin{tabular}{|c|c|c|}
\hline Tanımlayıcı Özellikler & & $\mathrm{N}=11(\%)$ \\
\hline \multirow[t]{2}{*}{ Cinsiyet } & kadın & $3(27,27)$ \\
\hline & erkek & $8(72,73)$ \\
\hline \multirow[t]{2}{*}{ Eğitim } & lise & $6(54,55)$ \\
\hline & üniversite & $5(45,45)$ \\
\hline \multirow[t]{2}{*}{ Tanı } & inme & $8(72,73)$ \\
\hline & travmatik beyin hasarı & $3(27,27)$ \\
\hline \multirow{2}{*}{$\begin{array}{l}\text { Hastalık öncesi çalışma } \\
\text { durumu }\end{array}$} & çalışıyordum & $9(81,82)$ \\
\hline & çalışmıyordum & $2(18,18)$ \\
\hline \multirow{3}{*}{$\begin{array}{l}\text { Hastalık sonrası çalışma } \\
\text { durumu }\end{array}$} & çalışıyordum & $0(0,00)$ \\
\hline & çalışmıyordum & $11(100,00)$ \\
\hline & & Ort $\pm S S$ \\
\hline Yaş & yıl & $34,45 \pm 3,70$ \\
\hline Etiyoloji tarihi & ay & $7,36 \pm 1,63$ \\
\hline
\end{tabular}

Tablo 2. Bireylerin Hastalığa Psikososyal Uyum-Özbildirim Ölçeği Sonuçları

\begin{tabular}{|c|c|c|c|}
\hline $\begin{array}{l}\text { Hastalığa Psikososyal Uyum- } \\
\text { Özbildirim Ölçeği- PAIS-SR }\end{array}$ & $\begin{array}{c}\mathrm{N}=11 \\
\text { Ort } \pm S S\end{array}$ & Min-Max & $\mathbf{N}(\%)$ \\
\hline Sağlık bakımına oryantasyon & $7,00 \pm 2,79$ & 3-13 & \\
\hline Mesleki çevre & $9,73 \pm 3,78$ & 3-14 & \\
\hline Aile çevresi & $9,18 \pm 4,56$ & 3-17 & \\
\hline Cinsel ilişkiler & $7,27 \pm 4,47$ & $0-13$ & -- \\
\hline Geniş aile ilişkileri & $4,27 \pm 2,61$ & $1-10$ & \\
\hline Sosyal çevre & $10,00 \pm 4,96$ & $5-17$ & \\
\hline Psikolojik baskı & $7,81 \pm 4,81$ & $1-16$ & \\
\hline \multirow{3}{*}{ Toplam } & \multirow{3}{*}{$54,81 \pm 16,70$} & İyi psikososyal uyum $(<35)$ & $2(18,18)$ \\
\hline & & Orta derecede psikososyal uyum (35-51) & $3(27,27)$ \\
\hline & & Kötü psikososyal uyum $(>51)$ & $6(54,55)$ \\
\hline
\end{tabular}

Bireyin hastalık öncesi kendini tanımlaması ile ilgili ifade örnekleri;

"Doğru". Çünkü kendimi yaşantıda öyle hisediyorum (a)

“İşkolik. Çünkü sürekli iş düşünüyordum” (b).

"Harika" (c).

"ilginç" (d).

"Çalışkan". Her gün namazımı kılardım. Tavlaya, okeye giderdim. Yeşilliklerde gezerdim (e)

"Güzel kitap okurdum" Başka şeylerle uğraşmaktansa kitap okurdum (f).

"Ağırbaşlı" (g).
"Mutlu" ( $h, k, l)$.

"Duruma göre hareket eden bir insandım" (ı).

Birey hastalık sonrası kendini tanımlaması ile ilgili ifade örnekleri;

"Yine doğru". Çünkü hiçbir zaman yaşantımda, işimde yanlışlık yapmadım (a)

"Mahvolmuş. Hayatımı mahvetti" (b,c,k).

"Mutlu, mutsuz". Insanlara mutlu görünüyorum ama umutsuzluğa kapıldığım için, kendi başıma kalınca mutsuz oluyorum (d).

"Üzgün”. Çünkü ayağımla kolum çalışmıyor. Her insan gibi ben de Cuma namazına gitmek, bir kişi zordayken 
ona yardım etmek istiyorum. Kimseye muhtaç olmadan ekmeğimi kazanmak (e).

“Üzgün, yorgun”. Bilmiyorum (f).

"Duygusal". Sürekli hastalığımla ilgili bir operasyon geçirmek kolay değil. Hep bunu ben mi yaşıycam diye korkuyorum"(g).

"Sakin" (h).

"Muhtaç bir insan oldum". Çünkü kendi başıma özgür hareket edemiyorum" (I,I).

Bireylerin hastalık süreci öncesi ve sonrası tanımlamalarına bakıldığında; özellikle hastalık sonrasında olumsuz duygular yaşadıkları, başka birine bağımlı olma durumu nedeni ile üzgün oldukları belirlendi.

Hastalık süreci ile ilgili yaşamlarındaki değişiklilere dair bireylerin ifade örnekleri;

"Tamamen alt üst olduk. Ailem bir tarafta, çocuklar bir tarafta, ben bir tarafta. İş dağıldı” (a).

"Tüm hayatım değişti. Çocuğa bakmak, yürümekte zorlanıyorum. Hastalık nedeni ile işe girmiyorum" (b).

"Herşey alt üst oldu. Tüm vucudum etkilendi. Top oynamak, çocuklarımla eğlenmek, eşimle beraber gezmek gibi birçok şey etkilendi. Bunlar gerçekten çok önemli" (c).

"Illeriye dönük planlar yapamıyorum. Yurtdışına kalıcı olarak çıkmayı düşünüyordum, şu anda düşünemiyorum. Böyle birinin iş sahibi olması zor, daha doğrusu yetersiz" (d).

Önceden telefon kullanıyordum, artık kullanmıyorum. Beyin açısından iyi olmaz çünkü. $\mathrm{Bu}$ durum benim için çok önemli. Televizyona bakamıyorum, kitap okuyamıyorum. Beynimi yormuyorum" (e).

"Birçok şeyi kendim yapamıyorum artık" (f,k,l).

"Hastalıktan dolayı çaresiz kaldığım durumlar oldu. Başkalarına muhtaç kaldığım durumlar oldu.

Ben malulen emekli olmak zorunda kaldım" (g).

"Dünyaya bakış açım değişti. Empati yapmaya başladım" (h).

"Gezmeyi, eğlenmeyi çok seven bir insandım. Şimdi sadece kendimle ilgileniyorum" (I).

Bireylerin ifadeleri incelendiğinde; olumsuz duygular içinde oldukları, özellikle aile içindeki rolleri, serbest zaman ve üretkenlik aktiviteleri ile ilgili zorluklar yaşadıkları belirlendi.

Bireylerin hastalık sonrası kaygılarına dair ifade örnekleri;

"İs nasıl olacak? Ben olmayınca diğerleri senin gibi yerine getiremezler" (a).

"Hastalığımın tekrar nüks etmesi" $(b, h)$

"Ne kadar iyileşeceğim konusunda kaygılıyım" $(c, d, k)$.
"İşlerimi kendim yapamayacak olmak" (e,l).

"Yeniden öğrenememek" (f).

"Kaygım yok" $(g, ı)$.

"Araç kullanamayacağımı düşünüyorum” (h).

Bireylerin hastalık sonrası kaygılarına dair ifade örnekleri incelendiğinde; genellikle hastalık süreci ve üretkenlik aktiviteleri ile ilgili kaygı taşıdıkları görüldü.

Bireylerin hastalık sonrası beklentilerine dair ifade örnekleri;

"Hiçbir şey beklemiyorum" (a,b).

"lyileşmek" (c,f,k).

"Kendim için birşey beklemiyorum. Oğlum için beklentilerim var. Onun benden çok üst seviyede yaşamasını istiyorum" (d).

"İşlerimi kendim yapabilmek" (e).

"Umutlarım var" $(g, h)$.

"Bir an önce kendimi toparlamak" (I).

"Kendime hedef belirlemek istiyorum. Daha önceden hedefim yoktu" (I).

Bireylerin hastalık sonrası beklentilerine dair ifadeler incelendiğinde; genellikle sağlıkları ile ilgili daha iyi olmak konusunda beklentide oldukları görüldü.

Bireylerin hastalık sonrası sosyal çevreleri ve ilişkileri ile ilgili ifadelerinden örnekler;

"Birkaç arkadaşım beni bıraktı. Tek sebebi hastalık. Ben kesinlikle böyle düşünüyorum. Aynı zamanda iyi dostlarım da var. Onlarla beraber hayata döndüm (a)." "Şu an için yok ama muhtemelen olacak (b). "

"Sosyal çevremde azalma oldu $(c, h, k)$."

"Değişiklikler oldu. Sosyal çevremde, genelde iş arkadaşlarımda. Onlarla görüşemiyorum. Onların işleri var, benim kadar boş değiller. Yalnız bırakmadılar ama, hepsi geldiler. Hızlı iyileşmem nedeni ile bu değişiklikler oldu (d)."

"Arkadaşlarım bana çok yardım etti. Ben hiçbir konuda dışlanmadım. Beni geziye götürdüler, pikniğe götürdüler. Benim hastalığımı bana unutturdular. Elimde olsa bende onlara aynı şeyi yapmak isterdim. Onlara minnettarım (e)."

"Olmadı" $(f, g, ı)$."

"Kimse beni saymıyor gibi geliyor. Belki de benim ön yargım olabilir, bilmiyorum (I)."

Bireylerin hastalık sonrası sosyal çevreleri ve ilişkileri ile ilgili ifadelerine bakıldığında; genellikle olumsuz duygular içinde oldukları belirlendi.

Bireylerin hayatlarında değiştirmek istedikleri şeyler incelendiğinde ise sekiz bireyin cevabı "hastalanmamak" dı. Diğer üç bireyin cevabı ise; "hayatımı komple değiştirmek", "eskisi gibi olmak" ve "malulen emeklilerin sosyal hakları ile ilgili bir çalışma yapmak" dı. 


\section{TARTIŞMA}

Bu çalışma genç yetişkin bireylerde EBH sonrası psikososyal uyumu incelemek amacı ile planlandı ve bu bireylerde psikososyal uyumun daha çok orta ve kötü düzeyde olduğu saptandı. Ayrıca bireylerin özellikle serbest zaman ve üretkenlik aktiviteleri ile ilgili olarak zorluk yaşadıkları belirlendi.

Literatürde EBH'nda psikososyal etkilenim ve adaptasyonla ilgili yapılan çalışmalar giderek artmaktadır. Bu çalışmaların sonuçları; sağlık durumundaki ani bir değişikliğin ardından bireyin veya ailenin değişim sürecini yönetmesine yardımcı olmak için psikososyal tedavilere ve müdahalelere yol gösterici olmuştur (Yates, 2003). EBH olan bireylerde psikososyal uyumu inceleyen bir çalışmada, çalışmayan bireylerin çalışan bireylere göre daha şiddetli anksiyete ve depresyon belirtileri gösterdiği saptanmıştır (Franulic ve ark., 2004). TBH tanısı olan yetişkin bireylerde dayanıklılık, uyum ve psikolojik işlevlerin ilişkisini inceleyen bir çalışmada ise; bu bireylerin psikolojik problemler ve psikososyal uyumsuzluk ile ilişkili olduğu belirlenen düşük dayanıklııı açısından riski altında oldukları bildirilmiştir (Bushnik, Lukow, Godwin ve ark., 2015).

İşlevsellik, Yetiyitimi ve Sağlığın Uluslarası Sınıflandırması (ICF), bir bireyin çevresel ve kişisel faktörler bağlamı içerisinde bozukluklar, aktivite limitasyonu ve katılım kısıtlılığı olarak işlevselliğin üç seviyesini ifade etmektedir. Bu konseptte düşünüldüğünde; psikososyal problemlerin, bireyin okul, sosyal yaşam, ev, serbest zaman ve spor aktiviteleri gibi günlük rutini gerçekleştirmesini olumsuz yönde etkileyerek aktivite limitasyonu ve katılım kısıtııı̆ına dolayısıyla da yaşam kalitesinin azalmasına neden olabileceği belirtilmektedir (Soo, Tate ve Brookes, 2014). Mevcut çalışmanın sonuçları ise literatürü destekler nitelikte olup, EBH tanısı almış genç yetişkin bireylerde psikososyal uyumun yeterli düzeyde olmadığına dikkat çekmektedir.

$\mathrm{Bu}$ çalışmada aile çevresi, cinsel ilişkiler, sosyal çevre ve psikolojik baskı alanlarının psikososyal uyum açısından etkilendiği görülmektedir. Sosyal destek, resmi ortamların dışında verilen herhangi bir destek olarak tanımlanabilir (Campbell, Wynne-Jones ve Dunn, 2011) ve yetişkinlerin sağlık ve sağlıkla ilgili parametrelerini önemli ölçüde etkileyebilir (Tomaka, Thompson ve Palacios, 2006). Kronik hastalığı olan yetişkinler için sosyal destek kritiktir
(Lett, Blumenthal, Babyak ve ark., 2005; Marino, Sirey, Raue ve ark., 2008). Sosyal destek veya baş etme yöntemleri gibi diğer faktörlerin de hastanın işlevsellik ve yeti yitimi üzerinde olumlu ve olumsuz etkisi olabilir (Franks, Campbell ve Shields, 1992).

Cinsel problemler hem beyin hasarı tanısı olan bireyler, hem de partnerleri açısından yaygındır. Yapılan bir çalışmada (Ponsford, 2003), beyin hasarı tanısı olan bireylerin \%54'ünün cinsel aktivite sıklığının azaldığını bildirmiştir. Yaralanan kişide meydana gelen duygusal ve davranışsal değişiklikler, partner ilişkisinde problemlere birincil neden olarak belirtilmiştir (Ponsford, 2003; Anderson, Parmenter ve Mok., 2002). Rol değişiklikleri duygusal sorunların kaynağı olarak da rapor edilmiştir. Eşler, karı koca ilişkisinden ziyade ebeveyn-çocuk gibi hissettiklerini bildirmişlerdir (Gosling ve Oddy, 1999). Bu çalışmada cinsel ilişkiler, psikososyal uyum açısından en çok etkilenen parametrelerden biridir. Bu sonuç literatürü destekler niteliktedir.

Çalışmanın bulguları göz önüne alındığında; EBH tanısı olan bireylerin bireylerin diyabet (Kaymaz ve Akdemir, 2016) ve kalp yetmezliği tanısı olan (Vural ve Karadakovan, 2016) bireylere göre sağlık bakımına oryantasyon açısından daha iyi düzeyde uyum sağladığı belirlenmiştir. $\mathrm{Bu}$ durum EBH sonrası bireylerin genellikle sağlık merkezindeki tedavisinin uzun sürmesi ve bu bireylerin sağlık personeli ile daha uzun süre bir arada olması nedeni ile olabilir.

Beyin hasarı, bireylerin kendileri ve toplum tarafından değer verilen rollere ve aktivitelere katılma yeteneğini olumsuz yönde etkileyen, hayatı değiştiren bir olaydır (Temkin, Corrigan, Dikmen ve ark., 2009). Beyin hasarı tanısı olan bireyler, arkadaşıklarda azalma, zamanla yalnızlığı artırma ve yeni ilişkiler kurma güçlüğü bildirmektedir (Seibert, Reedy, Hash ve ark., 2002; Hoofien, Gilboa, Vakil ve ark., 2001). Ev yönetimi ve ebeveynlik dahil olmak üzere yerel rolleri yerine getirme yeteneği etkilenir. Beyin hasarı olan kişilerin serbest zaman aktivitelerine katılma yetenekleri de genellikle azalır ve çoğu zaman sosyal izolasyonla karşılaşırlar (Kersel, Marsh, Havill ve ark., 2001; Jacobs, 1988). Bu çalışmada bireylerin ifadeleri göz önüne alındığında; sosyal çevrelerinin olumsuz etkilendiği ve serbest zaman aktiviteleri ile ilgili zorluk yaşadıkları belirlenmiştir. Ayrıca bireylerin tümü hastalık sonrası iş kaybı yaşamışlardır. Oysa; hastalık sonrası işe geri dönen bireyler, daha iyi sosyal uyumlara sahip olabilirler; bu da mevcut ilişkiler için sosyal destek sağlamanın yanı sıra, yakın ilişkiler oluşturma fırsatını artırabilir (Gill, Sander, Robins ve ark., 2011). Beyin hasarı rehabilitasyonunda, fonksiyonel bağımsızlığın iyileştirilmesinin, toplumsal 
katılım ve istihdama dönmenin beyin hasarından sonraki nihai hedefler olduğu kabul edilmiştir (Doig, Fleming ve Tooth, 2001; Winkler, Unsworth ve Sloan, 2006). Bununla birlikte Mazaux ve Richer (Mazaux ve Richer, 1998), EBH tanısı olan bireylerde serbest zaman ve sosyal aktivitelere dönmenin ve insan ilişkilerini sürdürmenin, işe dönmekten daha fazla olmasa da eşit derecede önemli olabileceğini öne sürmüştür.

Rehabilitasyonun beklenti, kimlik duygusu ve kabul gibi psikososyal bileşenleri, genellikle "karşılanmamış intiyaçlar" olarak kabul edilen önemli psikolojik kavramlardır (Bendz, 2003; Prigatano, 2011; Peoples, Satink ve Steultjens, 2011). Objektif işlevsellik önceliklerini temel alan ve tedavi sürecinde danışanların öznel deneyimini ve ihtiyaçlarını göz ardı eden uzmanlar, danışanların sorunlarına potansiyel olarak katkıda bulunabilir ve istemeden psikososyal uyum sağlamalarını engelleyebilirler. Tedavi hedeflerinin ve stratejilerinin önceliklerini yansıtmasını sağlamak için danışanlardan doğrudan tedavileri hakkında bilgi istenmelidir (Johnston, Goverover ve Dijkers, 2005). Bu nedenle $\mathrm{EBH}$ tanısı alan bireylerde nicel çalışmalar kadar nitel çalışmaların da yapılmasının önemli olduğu düşünülmektedir.

Literatürde nitel ve nicel yöntemlerin kullanıldığı bu konuda bir çalışmaya rastlanmamış olması; bu çalışmanın güçlü yönüdür. Çalışmanın limitasyonu ise; çalışmada kontrol grubunun olmamasıdır. İleride daha fazla bireyin dahil edildiği ve psikososyal uyumu etkileyen faktörlerin de incelendiği çalışmaların yapılması; beyin hasarı tanısı almış bireylerin müdahale programları açısından yol gösterici olacaktır.

\section{Kaynaklar}

Adaylar, M. (1995). Kronik hastalığı olan bireylerin hastalıktaki tutum, adaptasyon, algı ve öz-bakım yönelimleri (Yayınlanmamış doktora tezi). İstanbul Üniversitesi Sağlık Bilimleri Enstitüsü, İstanbul.

Anderson, M. I., Parmenter, T. R., \& Mok, M. (2002). The relationship between neurobehavioural problems of severe traumatic brain injury (TBI), family functioning and the psychological well-being of the spouse/caregiver: Path model analysis. Brain Inj, 16(9), 743-757. https://doi.org/10.1080/02699050210128906

Antonak, R. F., Livneh, H., \& Antonak, C. (1993). A review of research on psychosocial adjustment to impairment in persons with traumatic brain injury. J Head Trauma Rehabil, 8(4), 87-100. https://doi.org/10.1097/00001199-199312000-00009
Beck, C. M., Rawlins, R. P., \& Williams, S. S. (1984). Mental health-psychiatric nursing: A holistic life-cycle approach. Am J Nurs, 84(12), 1482.

Bendz, M. (2003). The first year of rehabilitation after a strokefrom two perspectives. Scand J Caring Sci, 17(3), 215-222. https://doi.org/10.1046/j.1471-6712.2003.00217.x

Bradt, J., Magee, W. L., Dileo, C., Wheeler, B. L., \& McGilloway, E. (2010). Music therapy for acquired brain injury. Cochrane Database Syst Rev, (7), 1-35. https://doi.org/10.1002/14651858.CD006787.pub2

Browne, G. B., Arpin, K., Corey, P., Fitch, M., \& Gafni, A. (1990). Individual correlates of health service utilization and the cost of poor adjustment to chronic illness. Med Care, 28(1), 4358. https://doi.org/10.1097/00005650-199001000-00006

Bruyère, S. M., Van Looy, S. A., \& Peterson, D. B. (2005). The international classification of functioning, disability and health: Contemporary literature overview. Rehabilitation Psychology, 50(2), 113. https://doi.org/10.1037/00905550.50.2.113

Bushnik, T., Lukow, H. R., Godwin, E. E., Marwitz, J. H., Mills, A., Hsu, N. H., \& et al. (2015). Relationship between resilience, adjustment, and psychological functioning after traumatic brain injury: A preliminary report. J Head Trauma Rehabil, 30(4),

241-248. https://doi.org/10.1097/HTR.0000000000000137

Campbelll, P., Wynne-Jones, G., \& Dunn, K. M. (2011). The influence of informal social support on risk and prognosis in spinal pain: A systematic review. Eur J Pain, 15(5), 444.e1444.e14. https://doi.org/10.1016/j.ejpain.2010.09.011

DeDios-Stern, S., \& Lee, E.-J. (2017). Blame, coping, and psychosocial outcomes in caregivers of individuals with brain injury. Rehabilitation Psychology, 62(3), 353362. https://doi.org/10.1037/rep0000143

Derogatis, L. R. (1986). The psychosocial adjustment to illness scale (PAIS). J Psychosom Res, 30(1), 77-91. https://doi.org/10.1016/0022-3999(86)90069-3

Doig, E., Fleming, J., \& Tooth, L. (2001). Patterns of community integration 2-5 years post-discharge from brain injury rehabilitation. Brain Inj, 15(9), 747-762. https://doi.org/10.1080/02699050119845

Erşan, E. E., Kelleci, M., \& Baysal, B. (2013). Kalp hastalarında psikososyal uyum, depresyon, anksiyete ve stres düzeylerine bir bakış. Klinik Psikiyatri, 16(4), 214-224.

Feigin, V. L., Forouzanfar, M. H., Krishnamurthi, R., Mensah, G. A., Connor, M., Bennett, D. A., \& et al. (2014). Global and regional burden of stroke during 1990-2010: Findings from the Global Burden of Disease Study 2010. Lancet, 383(9913), 245-255. https://doi.org/10.1016/S01406736(13)61953-4

Franks, P., Campbell, T. L., \& Shields, C. G. (1992). Social relationships and health: The relative roles of family functioning and social support. Soc Sci Med, 34(7), 779-788. https://doi.org/10.1016/0277-9536(92)90365-W

Franulic, A., Carbonell, C. G., Pinto, P., \& Sepulveda, I. (2004). Psychosocial adjustment and employment outcome 2, 5 and 10 years after TBI. Brain Inj, 18(2), 119-129. https://doi.org/10.1080/0269905031000149515

George, E., \& Engel, L. (1980). The clinical application of the biopsychosocial model. American journal of Psychiatry, 137(5), 535-544.

Gill, C. J., Sander, A. M., Robins, N., Mazzei, D., \& Struchen, M. A. (2011). Exploring experiences of intimacy from the viewpoint of individuals with traumatic brain injury and their 
partners. J Head Trauma Rehabil, 26(1), 56-68. https://doi.org/10.1097/HTR.0b013e3182048ee9

Gosling, J., \& Oddy, M. (1999). Rearranged marriages: Marital relationships after head injury. Brain Inj, 13(10), 785-796. https://doi.org/10.1080/026990599121179

Güngen, C., Ertan, T., Eker, E., Yaşar, R., \& Engin, F. (2002). Reliability and validity of the standardized Mini Mental State Examination in the diagnosis of mild dementia in Turkish population. Turk Psikiyatri Derg, 13(4), 273-281.

Hoofien, D., Gilboa, A., Vakil, E., \& Donovick, P. J. (2001). Traumatic brain injury (TBI) $10-20$ years later: A comprehensive outcome study of psychiatric symptomatology, cognitive abilities and psychosocial functioning. Brain Inj, 15(3), 189-209. https://doi.org/10.1080/026990501300005659

Honan, C. A., McDonald, S., Tate, R., Ownsworth, T., Togher, L., Fleming, J., ... \& Francis, H. (2019). Outcome instruments in moderate-to-severe adult traumatic brain injury: recommendations for use in psychosocial research. Neuropsychological Rehabilitation, 29(6), 896-916. https://doi.org/10.1080/09602011.2017.1339616

Jacobs, H. E. (1988). The Los Angeles head injury survey: Procedures and initial findings. Arch Phys Med Rehabil, 69(6), 425-431.

Johnston, M. V., Goverover, Y., \& Dijkers, M. (2005). Community activities and individuals' satisfaction with them: quality of life in the first year after traumatic brain injury. Arch Phys Med Rehabil, 86(4), 735-745. https://doi.org/10.1016/j.apmr.2004.10.031

Kaymaz, T. T., \& Akdemir, N. (2016). Diyabetli Bireylerde Hastalığa Psikososyal Uyum. Journal of Psychiatric Nursing, 7(2), 61-67.

Kersel, D. A., Marsh, N. V., Havill, J. H., \& Sleigh, J. W. (2001). Psychosocial functioning during the year following severe traumatic brain injury. Brain Inj, 15(8), 683-696. https://doi.org/10.1080/02699050121354

Lett, H. S., Blumenthal, J. A., Babyak, M. A., Strauman, T. J., Robins, C., \& Sherwood, A. (2005). Social support and coronary heart disease: Epidemiologic evidence and implications for treatment. Psychosom Med, 67(6), 869-878. https://doi.org/10.1097/01.psy.0000188393.73571.0a

Londono, Y., \& McMillan, D. E. (2015). Psychosocial adaptation: An evolutionary concept analysis exploring a common multidisciplinary language. J Adv Nurs, 71(11), 2504-2519. https://doi.org/10.1111/jan.12723

Marino, P., Sirey, J. A., Raue, P. J., \& Alexopoulos, G. S. (2008). Impact of social support and self-efficacy on functioning in depressed older adults with chronic obstructive pulmonary disease. Int $\mathrm{J}$ Chron Obstruct Pulmon Dis, 3(4), 713-718. https://doi.org/10.2147/copd.s2840

Mazaux, J. M., \& Richer, E. (1998). Rehabilitation after traumatic brain injury in adults. Disabil Rehabil, 20(12), 435-447. https://doi.org/10.3109/09638289809166108

McGillion, M., Watt-Watson, J., Kim, J., \& Yamada, J. (2004). A systematic review of psychoeducational intervention trials for the management of chronic stable angina. J Nurs Manag, 12(3), 174-182. https://doi.org/10.1111/j.1365-2834.2004.00472.x

McGillion, M. H., Watt-Watson, J., Stevens, B., LeFort, S.
M., Coyte, P., \& Graham, A. (2008). Randomized controlled trial of a psychoeducation program for the self-management of chronic cardiac pain. J Pain Symptom Manage, 36(2), 126140. https://doi.org/10.1016/j.jpainsymman.2007.09.015

Menon, D. K., \& Bryant, C. (2019). Time for change in acquired brain injury. Lancet Neurology, 18(1), 28. https://doi.org/10.1016/S1474-4422(18)30463-0

Ownsworth, T., \& Fleming, J. (2005). The relative importance of metacognitive skills, emotional status, and executive function in psychosocial adjustment following acquired brain injury. $J$ Head Trauma Rehabil, 20(4), 315-332. https://doi.org/10.1097/00001199-200507000-00004

Peoples, H., Satink, T., \& Steultjens, E. (2011). Stroke survivors' experiences of rehabilitation: A systematic review of qualitative studies. Scand J Occup Ther, 18(3), 163-171. https://doi.org/10.3109/11038128.2010.509887

Ponsford, J. (2003). Sexual changes associated with traumatic brain injury. Neuropsychol Rehabil, 13(1-2), 275-289. https://doi.org/10.1080/09602010244000363

Prigatano, G. P. (2011). The importance of the patient's subjective experience in stroke rehabilitation. Top Stroke Rehabil, 18(1), 30-34. https://doi.org/10.1310/tsr1801-30

Rankin, J. (1957). Cerebral vascular accidents in patients over the age of 60: II. Prognosis. Scott Med J, 2(5), 200-215. https://doi.org/10.1177/003693305700200504

Seibert, P. S., Reedy, D. P., Hash, J., Webb, A., Stridh-Igo, P., Basom, J., \& et al. (2002). Brain injury: Quality of life's greatest challenge. Brain Inj, 16(10), 837-848. https://doi.org/10.1080/02699050210131939

Soo, C., Tate, R., \& Brookes, N. (2014). Psychosocial adjustment following acquired brain injury in childhood and adolescence: Executive, behavioural and emotional contributions. Brain Inj, 28(7), 906-914. https://doi.org/10.3109/02699052.2014.888762

Sullivan, M. J., \& Hawthorne, M. H. (1996). Nonpharmacologic interventions in the treatment of heart failure. J Cardiovasc Nurs, 10(2), 47-57. https://doi.org/10.1097/00005082199601000-00005

Temkin, N. R., Corrigan, J. D., Dikmen, S. S., \& Machamer, J. (2009). Social functioning after traumatic brain injury. J Head Trauma Rehabil, 24(6), 460-467. https://doi.org/10.1097/HTR.0b013e3181c13413

Tomaka, J., Thompson, S., \& Palacios, R. (2006). The relation of social isolation, loneliness, and social support to disease outcomes among the elderly. J Aging Health, 18(3), 359-384. https://doi.org/10.1177/0898264305280993

Vural Doğru, B., \& Karadakovan, A. (2016). Kalp Yetersizliği Olan Yaşlı Hastalarda Psikososyal Uyum ve Yaşam Kalitesi Arasındaki İlişkinin Değerlendirilmesi. Kardiyovasküler Hemşirelik Dergisi, $\quad 7(13), \quad$ 88-104. https://doi.org/10.5543/khd.2016.02886

World Health Organization. (2001). International classification of functioning, disability and health : ICF. World Health Organization. https://apps.who.int/iris/handle/10665/42407

Winkler, D., Unsworth, C., \& Sloan, S. (2006). Factors that lead to successful community integration following severe traumatic brain injury. J Head Trauma Rehabil, 21(1), 8-21.

Yates, P. J. (2003). Psychological adjustment, social enablement and community integration following acquired brain injury. Neuropsychol Rehabil, 13(1-2), 291-306. https://doi.org/10.1080/09602010244000408 